\title{
Implementing Assessment Policy: Considering the Bifactor Teachers' Satisfaction Criterion
}

\author{
Mohamad Sahari Nordin ${ }^{1, *}$, Tunku Badariah Tunku Ahmad ${ }^{1}$, Mohd Burhan Ibrahim, \\ Enas Said Abulibdeh ${ }^{2}$ \\ ${ }^{1}$ Kulliyyah of Education, International Islamic University Malaysia, Malaysia \\ ${ }^{2} \mathrm{Al}$ Ain University of Science and Technology, United Arab Emirates
}

Received June 28, 2019; Revised September 5, 2019; Accepted September 12, 2019

Copyright $(2019$ by authors, all rights reserved. Authors agree that this article remains permanently open access under the terms of the Creative Commons Attribution License 4.0 International License

\begin{abstract}
The study examined teachers' general satisfaction and specific satisfactions in implementing assessment policy. First it confirmed the validity of a four-factor teacher's satisfaction construct. Next it identified the best-fitting measure of teacher's satisfaction among four theoretically viable measures, namely a uni-dimension satisfaction construct, four-factor construct, second-order factor construct, and a bi-factor measure that comprised general and specifics factors. Finally, the study tested whether teachers' agreement with the implementation of nation-wide assessment policy related to the best-fitting satisfaction model, which was the bi-factor model. A total of 2,374 teachers nested in 300 randomly selected schools in Malaysia were surveyed using a 15-item instrument. The results supported the hypotheses that the four-factor measure was adequate to explain the variability of teachers' responses to the satisfaction items, the bi-factor model was the best-fitting model, and teachers' endorsement of the implementation of assessment policy supported the teachers' general satisfaction, satisfaction towards workload, and satisfaction towards pay and benefits.
\end{abstract}

Keywords Teacher's Satisfaction, Bi-factor Model, Assessment Policy, Policy Implementation

\section{Introduction}

Hoppock's classic work on teacher's satisfaction has sustained interest and research for more than 80 years. Hoppock defined job satisfaction as "any combination of psychological, physiological and environmental circumstances that causes a person truthfully to say, 'I am satisfied with my job" [1]. Teacher's satisfaction can be logically and empirically linked to a plethora of key educational outcomes, and has been a traction among educational, management, and research communities. Satisfied teachers are found to be more effective, an outcome that contributes immensely to the accomplishments of an education system [2]. Teacher's satisfaction is reliably and positively related to teaching interest, instructional competency, job performance, professional commitment and engagement, emotional adjustment, improved health, enhanced work environments, and more importantly, student outcomes. Not surprisingly, high satisfaction level is negatively related to job fatigue, stress, turnover intention, attrition rate, and burnout [3]. The inverse relationship is true for teachers with little or no satisfaction with their work, who find little enjoyment in what they do at school daily.

Teacher's satisfaction makes a huge difference in student learning, student achievement, and performance. On average, higher achievements are recorded for students taught by satisfied teachers than for those instructed by less satisfied ones [4]. It is for this reason that scholars are motivated to unearth the factors that engender greater levels of teacher's satisfaction. To date most studies concurred with the notion of motivator-hygiene determinants, which is one of the most durable theories of job satisfaction [5]. The theory suggests that job satisfaction is a function of two antecedents-motivators and hygiene - that explain the variability of teacher's satisfaction. Motivators are the needs, desires, wants, or drives for good feelings, achievement, recognition, responsibility, and opportunities for advancement and growth that are inherent within teachers. The motivators are related to facets of the job that teachers would want to perform and feel satisfied with. Examples of motivators are attitudes towards pay and job benefits, reward and recognition, the work itself, and opportunities for professional development. The hygiene factors are the external drivers of job satisfaction that include the working 
environment such as organizational policies, general management, and relationships with co-workers and superiors.

Although we are well-informed about the influence of the motivator-hygiene factors on teacher's satisfaction, there are several concerns that need to be addressed. First, most studies treated job satisfaction as a unidimensional construct, in which the focus has been the overall or general teacher's satisfaction even in cases where multidimensional instruments were used.

At the same time, it is also important to recognize the impacts of an external hygiene factor on the specific factors of teacher's satisfaction. There is a possibility that an external factor could exert differential effects on teacher general dan specific satisfactions. For example, the implementation of nation-wide policies may not incur any impact on teacher satisfaction in general, teachers may not feel happy or satisfied with the additional workload they expect would come with the policy change. Thus far, individual studies have primarily reported on the relationships between the antecedent (the policy in question) with either general teacher's satisfaction or facets of teacher's satisfaction [6]. Apparently the effects on both the general and specific satisfactions are hardly available. This gap in understanding calls for a bi-factor modeling of teacher satisfaction. The model assumes the coexistence of: (a) a general factor representing shared variance among all the indicators; and (b) specific factors, in which variance over and above the general factor is shared among clusters of items that are similar in content. The present study primarily aimed to address this concern.

Second, the impact of assessment policy implementation on teacher's satisfaction has not been given much attention even though it is an important hygiene factor. In heavily centralized education systems, that of Malaysia included, policy-related decision making, planning, and implementation directives are continuously enforced by the authorities at the central education agencies. Since 2011, for example, several major changes in assessment policy have been implemented in Malaysia. Three of the changes were: (i) the introduction of a nation-wide school-based assessment (2011); (ii) repeal of the standardized Lower Secondary Evaluation (2013); and (iii) introduction of a standardized Form Three assessment (2014) that emphasizes assessing students' higher-order thinking. While change is constant, excessive and frequent changes can undermine teachers' skills, efficacy, attitudes, motivation and perceptions, which would consequently define their satisfaction. Some teachers may agree with the implementation of new policies [7], while others may become cynical and less satisfied $[8,9,10]$. It is the lack of clarity on this matter that motivates the undertaking of the present study.

\section{Objectives}

The study aimed to determine the influence of a national assessment policy implementation on Malaysian teachers' satisfaction and its specific facets, which include satisfaction towards workload, pay and benefits, professional growth, and interpersonal relationships. Precisely, the first objective was to identify the good fit of a four-factor teacher's satisfaction construct, examining the psychometric properties of teacher's satisfaction measure in terms of convergent validity, discriminant validity, and construct reliability. The second objective was to identify the best-fitting model of teacher satisfaction. Four competing, non-nested teacher satisfaction models were tested, namely (i) a one-factor model, (ii) a four-factor model, (iii) a second-order factor model, and (iv) a bi-factor model. The final objective was to validate the influence of a hygiene factor, i.e. teachers' agreement with the policy implementation, on the general and specific satisfaction factors.

\section{Bi-factor Teacher's Satisfaction Model}

There still is a lack of consensus among scholars about the meaning of job satisfaction, and this has generated enduring debates about the nature of the construct. On the one hand, teacher's satisfaction is considered as an attitudinal disposition [11]. It is a unidimensional construct that indicates the teacher's taste, feelings, positive state of emotion, and sense of fulfilment about the job. On the other hand, teacher's satisfaction has also been conceived as a socially constructed cognitive judgment about the job [12]. It is the result of teachers' systematic and logical assessment of the various dimensions or facets of their teaching job. Thus, apart from satisfaction in general, teachers may also positively or negatively assess the specific aspects of the job--commonly agreed to encompass workload, pay and benefits, opportunities for professional growth, and interpersonal relationship as the underlying dimensions. Collectively, as depicted in Fig. 1, the general and specific factors make up a bi-factor model of teacher's satisfaction. 


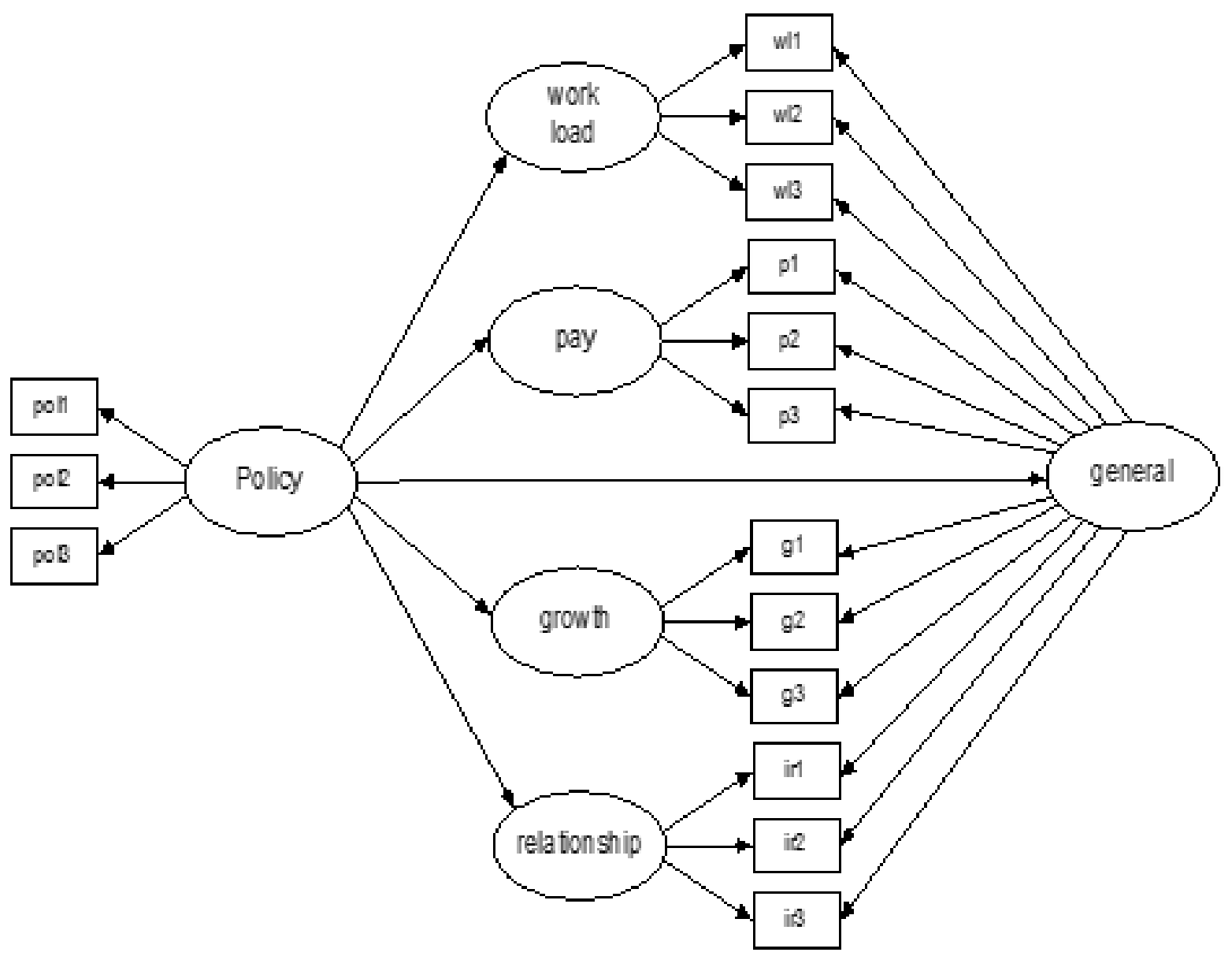

Figure 1. Hypothesized Model of Policy Implementation and Teachers' Bi-factor Satisfaction

Fig. 1 contains the bi-factor teacher's satisfaction construct and its antecedent (i.e. agreement with the implementation of assessment policy). The bi-factor model consists of a general satisfaction factor and the specific satisfaction towards the work itself (workload), pay and benefits (pay), professional advancement and growth (growth), and interpersonal relationship (relationship). These dimensions of teacher's satisfaction are structurally distinct; the general and specific factors coexist in a valid and reliable bi-factor model. For example, a teacher may find his or her work, pay and opportunities for advancement highly satisfying, but not their relationships with peers, or vice versa.

Also, each facet may have its own antecedents and consequences. A new policy implementation may, for example produce differential effects on teachers' general and specific satisfactions. Although some may be acquiescent to the policy change, others may perceive it as doctrinaire, authoritarian, or rigid, placing too strict a measure on how they should perform. Therefore, even though they agree with the policy, the teachers may also find themselves "subject to work intensification and bureaucratization, increased public scrutiny and greater accountability" [9], which would affect their satisfaction with workload. Put it differently, teachers' acquiescence with a policy implementation may produce inconsistent outcomes on general satisfaction and satisfaction with workload.

Suppose the preceding argument is valid, it is imperative to examine whether policy implementation would exert simultaneous, albeit differential, effects on general teacher's satisfaction, and on the specific satisfaction factors over and above the general factor. Thus, the study expected that:

H1: A four-dimensional teacher's satisfaction model is valid and reliable.

$\mathrm{H}$ : Teachers' general and specific satisfactions constitute an adequate bi-factor representation of teacher job's satisfaction.

H3: Teachers' general and specific satisfactions are the independent outcomes of their endorsement of the national education policy implementation.

\section{Method}

The sample of the study comprised teachers from 300 schools who volunteered to participate in the survey. The schools, $61.5 \%$ of which were primary, were randomly 
chosen from all schools in the 14 Malaysian states, with $60.5 \%$ of them located in urban areas. The total number of teachers who participated in the study were 2,374 . This relatively large sample size allows for the estimation of parameters at $\pm 3 \%$ margin of error, with $95 \%$ level of confidence. It also fulfills the large sample size requirement in a causal modelling procedure.

In terms of background characteristics, the data showed that the sample did not seriously deviate from the characteristics of the larger teacher population in Malaysia. The sample was $80.3 \%$ female with an average teaching experience of 15.3 years. The majority (64.2\%) had at least a bachelor's degree while the remaining teachers were high-school graduates.

The study used a 15 -item questionnaire that measured the variables of interest. The items were related to the five-factor model. These are the manifested indicators of the antecedent factor (endorsement of policy implementation), general satisfaction, and four specific satisfaction variables, namely "workload," "pay," "growth," and "relationship." Each construct was represented by three 5-point Likert items adapted from earlier studies, which included the Job Descriptive Index and Teacher Job Satisfaction Questionnaire [13, 14].

The data were subjected to confirmatory factor analysis (CFA), bi-factor analysis, and structural equation modelling using the AMOS (version 20) model-fitting program. The models were estimated on the basis of the covariance matrix. Maximum likelihood estimation procedure was applied to produce estimates of defensible properties. The adequacy of each model was examined using the following good-fit statistics: (i) consistency of the measurement model with the data, and (ii) reasonableness of the parameter estimates. Comparative fit index (CFI), root mean square error of approximation (RMSEA), and Akaike information criterion (AIC) were used as the fit indexes. In addition, this study assessed the psychometric properties of the bi-factor solution $[15,16]$. Specifically, four bi-factor indices were computed: (i) the explained common variance (ECV), (ii) percentage of uncontaminated correlations (PUC), which indicates the percentage of covariance terms related to the general factor, (iii) Omega hierarchical $\left(\mathrm{G}_{\mathrm{H \& HS}}\right)$, the indicators of model-based reliability, and (iv) construct replicability of each factor ( $\mathrm{H}$ index).

\section{Results}

\subsection{Adequacy of the Four-Factor Teacher Satisfaction Measure}

The CFA evaluated the adequacy of the four-factor measurement of teacher's satisfaction. The data showed that the model satisfied the requirements deemed necessary for a fitting measurement model; $\chi 2(48)=405.62$; CFI $=.96$; RMSEA $=.056$, CI: .051, .061). These statistics suggested that the four-factor teacher's satisfaction model was consistent with the data. Table 1 shows the results of the CFA, in terms of standardized factor loadings, average variance extracted (AVE), and composite reliability (CR).

Table 1. FACTOR LOADING, AVERAGE VARIANCE EXTRACTED, AND COMPOSITE RELIABILITY

\begin{tabular}{|c|c|c|c|c|}
\hline Construct & Items & $\begin{array}{c}\text { Loading } \\
*\end{array}$ & $\begin{array}{c}\text { AV } \\
\text { E }\end{array}$ & $\mathrm{CR}$ \\
\hline \multirow{3}{*}{ Workload } & Teaching load & .75 & \multirow{3}{*}{.53} & \multirow{3}{*}{.77} \\
\hline & Class size & .55 & & \\
\hline & Administrative tasks & .78 & & \\
\hline \multirow{3}{*}{$\begin{array}{l}\text { Pay and } \\
\text { Benefits }\end{array}$} & Salary & .85 & \multirow{3}{*}{.62} & \multirow{3}{*}{.83} \\
\hline & Prestige & .66 & & \\
\hline & Fringe benefits & .84 & & \\
\hline \multirow{3}{*}{ Growth } & $\begin{array}{l}\text { Opportunities to be } \\
\text { innovative in } \\
\text { teaching and learning }\end{array}$ & .69 & \multirow{3}{*}{.63} & \multirow{3}{*}{.83} \\
\hline & $\begin{array}{l}\text { Opportunities to } \\
\text { attend training in } \\
\text { leadership and } \\
\text { administration }\end{array}$ & .85 & & \\
\hline & $\begin{array}{l}\text { Opportunities to } \\
\text { attend professional } \\
\text { development } \\
\text { program in teaching } \\
\text { and learning }\end{array}$ & .83 & & \\
\hline \multirow{3}{*}{ Relationship } & Collegiality climate & .64 & \multirow{3}{*}{.41} & \multirow{3}{*}{.67} \\
\hline & $\begin{array}{c}\text { Relationship with } \\
\text { other teachers }\end{array}$ & .51 & & \\
\hline & $\begin{array}{l}\text { Opportunities to } \\
\text { comment and } \\
\text { recommend }\end{array}$ & .75 & & \\
\hline
\end{tabular}

*All loadings are statistically significant

All loadings, ranging between .51 and .85 , were substantially and statistically significant. The specific factors of teacher's satisfaction, namely workload, pay and benefits, professional growth, and interpersonal relationships were correlated. The CRs exceeded .70, with the exception of interpersonal relationship. The average variance extracted (AVE) for three of the constructs also exceeded the variance caused by its measurement error; the threshold being .50. The correlations among constructs ranged between .35 and .73 ; the value of the maximum shared variance was .53 . Thus the multidimensional measure of teacher satisfaction demonstrated sufficient properties of reliability, convergent validity and discriminant validity.

\subsection{Best Fitting Measurement of Teacher's Satisfaction}

Four models of teacher's satisfaction measures were tested, namely: (i) Model A (a one-factor satisfaction model); (iii) Model B (containing the four correlated specific factors); (iii) Model C (containing the four specific satisfaction factors loaded on one second-order factor); and (iv) Model D, which is a bi-factor model of teacher satisfaction. 
Table 2. FIT STATISITICS OF COMPETING MODELS

\begin{tabular}{|c|c|c|c|c|}
\hline Indicator/ Model & A & B & C & D \\
\hline \multicolumn{5}{|c|}{ Fit Information } \\
\hline$\chi 2$ & 3968 & 405 & 622 & 370 \\
\hline $\mathrm{df}$ & 54 & 48 & 50 & 42 \\
\hline $\mathrm{CFI}$ & .599 & .963 & .941 & .966 \\
\hline RMSEA & .175 & .056 & .069 & .057 \\
\hline AIC & 4040 & 490 & 701 & 466 \\
\hline
\end{tabular}

Table 2 shows that the models appeared to fit the data reasonably well with the exception of Model A, the one-factor solution. The fit indexes of the unidimension satisfaction measure fell short of the conventionally acceptable cutscores of a fitting model [CFI < .95; RMSEA > .06; AIC being the largest comparatively]. On the other extreme, the least restrictive bi-factor model (Model D), yielded indicators of the best fit to the data in terms of CFI (.97), RMSEA (.057, CI: .052, .063), and the smallest AIC (466). While all factor loadings were significant, almost all indicators related to growth and interpersonal relationship loaded stronger on the general factor than on their respective specific factors (Fig. 2). In contrast, all indicators of workload and pay loaded stronger on their specific factors. The variances of the general and specific factors were statistically significant; each specific factor explained a substantial amount of variance above and beyond the general factor.
The bi-factor teacher's satisfaction measure also offers support for the use of separate scores of general satisfaction and each specific satisfaction [15]. The data showed that for the general factor the expected common variance $(\mathrm{ECV})$, i.e. the ratio of variance accounted for by the general factor over the variance accounted for by the specific factors, was not dominant; it was merely .42 . While the percentage of uncontaminated correlations (PUC) was .82 , the $\mathrm{GO}_{\mathrm{H}}$ and $\mathrm{H}$ index were .66 and .82 , respectively. For the specific factors, the ECVs ranged from .35 to .80 , over and beyond the variance accounted for by the general factor; $\mathrm{GD}_{\mathrm{HS}}$ ranged between .47 and $.78 ; \mathrm{H}$ values were between .47 and .89 . These results suggest that there is no evidence of a dominant unidimensional satisfaction structure in lieu of a multidimensional structure [17]. Hence the use of separate scores for the general factor and specific factors as the criteria in a causal model was in order.

\subsection{Relationship between Endorsement of Assessment Policy and Bi-factor Satisfaction}

To assess the relationships between the implementation of assessment policies on both the specific and general factors, the study applied structural equation modelling. The hypothesized relationships fit the data adequately $\left(\chi^{2}\right.$ $=524.86, \mathrm{df}=73, \mathrm{p}=.001, \mathrm{RMSEA}=.051$ and CFI $=.97)$. Fig. 2 depicts the results of the full SEM.

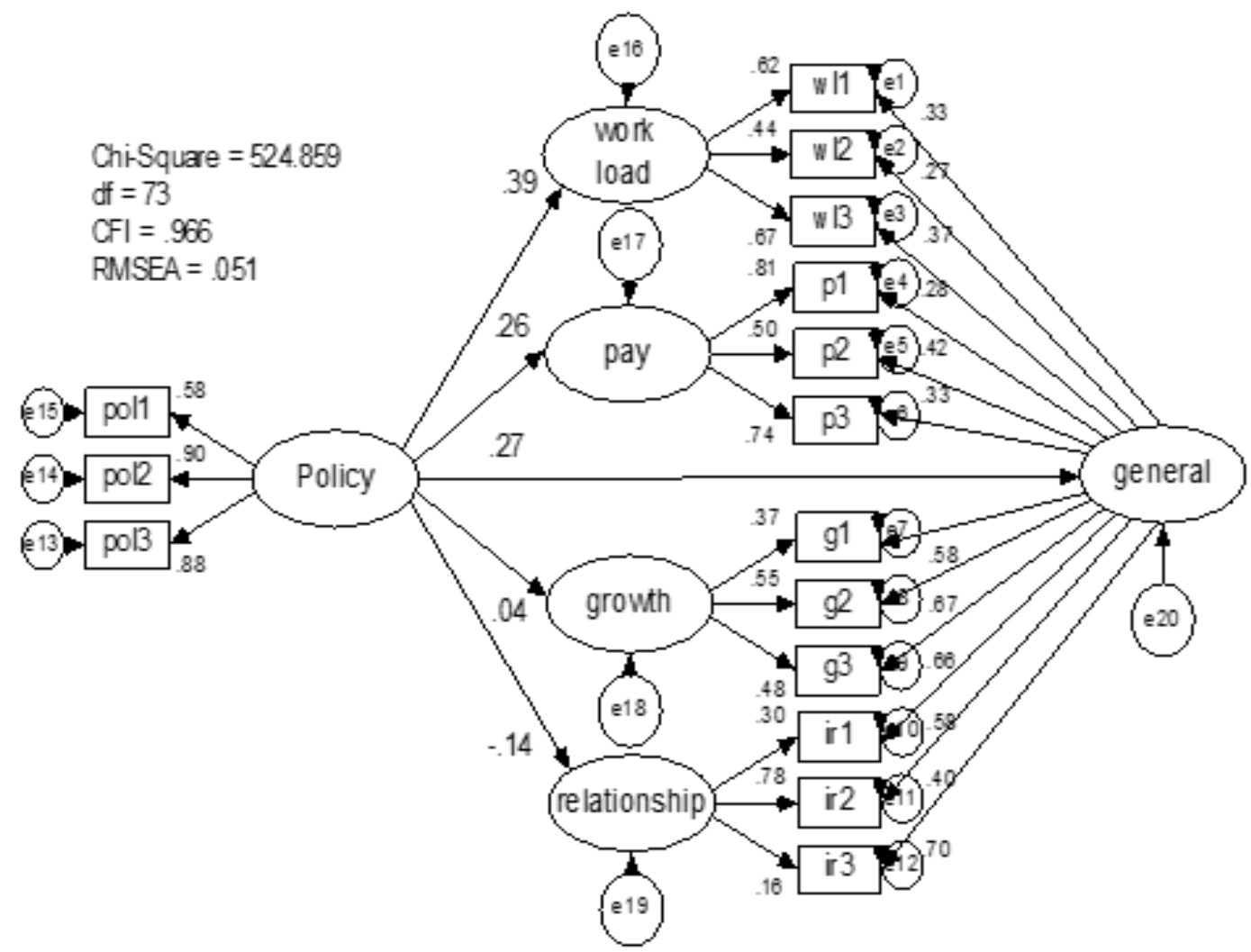

Figure 2. Policy Implementation and Bi-factor Satisfaction Relationships 
The results indicated that teachers' endorsement of assessment policy was positively related to their general job satisfaction $(\beta=.27, p=.001)$. It could be inferred that teachers who agreed with changes in the assessment policy reported higher levels of general satisfaction. On the same note, their agreement with the policy implementation was positively matched with two of the specific satisfactions, which were workload $(\beta=.39, \mathrm{p}=.001)$ and pay satisfaction $(\beta=.26, p=.001)$. After taking into account the impact on general satisfaction, the endorsement of assessment policy still has a significant relationship with teachers' satisfaction with workload and pay. In fact, teachers' agreement with the policy exerted the strongest influence on workload satisfaction. However, favourable endorsement of the policy change was not reliably associated with teacher satisfaction with interpersonal relationship $(\beta=.04, p=.027)$, or with the satisfaction towards growth and professional development $(\beta=-.14$, $p$ $=.039$ ).

\section{Conclusions}

The study revealed several noteworthy results that extended the findings of previous research. First, the results provided support that teacher's satisfaction is a multidimensional construct. The four specific satisfaction factors are teachers' workload, pay and benefits, professional advancement and growth, and interpersonal relationship. These factors are distinct, although somewhat correlated. Similar specific factors have been found in earlier studies $[12,13]$.

Second, the study extracted an adequate bi-factor teacher satisfaction measure. The data demonstrated the prevalence of a superordinate general satisfaction factor, which directly explains the covariation among the observed indicators. Over and beyond the general factor, the data yielded reliable and replicable specific satisfaction factors. Thus, the innovative approach to measuring the teacher's satisfaction construct partials out the mistake of using a summated score to represent general teacher's satisfaction. A summated teacher's satisfaction variable combines multiple dimensions of the satisfaction construct into a single summated score, and that procedure would shortchange our understanding about why and how external factors, such as a nationwide policy implementation, affect teacher satisfaction.

Evidently, the specific aspects of teacher's satisfaction had been affected differentially by the predictor. On the one hand, teacher's general satisfaction was consistent with their agreement with policy implementation. Similar effects of teachers' endorsement were observed in teacher's satisfaction with workload and pay and benefits. But, there were no reliable links between their endorsement of assessment policy implementation and satisfaction with professional advancement and interpersonal relationships. This finding is important for planning, managing, implementing, and reviewing education policies and practices.

Its contributions notwithstanding, the findings are constrained within the study's framework. To address its shortcomings, replication of the findings is imperative. For the bi-factor teacher's satisfaction measure to be of theoretical and practical use, it is important to cross-validate the findings, in particular the validity of the bi-factor measure, in different educational settings and contexts. Second, future studies may examine the measurement invariance of the bi-factor model. Future data collection should allow for multiple group analysis, and may use other teacher's satisfaction measures and teacher's characteristics such as gender, age, educational attainment, and culture. Finally, it would be substantially informative if the bi-factor model is treated as the predictors or criteria in research on teacher's satisfaction.

\section{REFERENCES}

[1] R. Hoppock, "Job satisfaction," Harper and Brothers, New York, p. 47, 1935.

[2] A. Pepe, L. Addimando, and G. Veronese, "Measuring teacher job satisfaction: Assessing invariance in the teacher job satisfaction scale (TJSS) across six countries," European Journal of Psychology., vol. 13, no. 3, pp. 396416, 2017.

[3] Y. I. Yorulmaz, I. Colak, and Y. Altinkurt, "A meta-analysis of the relationship between teachers' job satisfaction and burnout," Eurasian Journal of Educational Research, vol. 17, no. 71, pp. 175-192, 2017.

[4] V. S. Ina, M. O. Martin, P. Foy, and A. Arora, International Results in Mathematics TIMMS 2011, TIMSS \& PIRLS International Study Center, Chestnut Hill: MA, USA, 2012.

[5] F. Hergberg, B. Mausner, and B. B. Snyderman, "The motivation to work," 2nd edition, with John Wiley: New York, 1959.

[6] C. L. Chin, "The Influence of Job Satisfaction on Employee Turnover Intention in the Manufacturing Industry of Malaysia," vol. 1, no. 2, pp. 53-63, 2018.

[7] A. K. Thibodeaux, H. County, and C. A. Labat, "The effects of leadership and high-stakes testing on teacher retention," vol. 19, no. 1, pp. 227-250, 2015.

[8] M.A. Mohd Noor and L.P. Symaco, Education policies and practices in Malaysia. In: M. Samuel, M. Tee, and Symaco L. (eds), "Education in Malaysia. Education in the Asia-Pacific Region: Issues, concerns and prospects," vol. 39, pp. 67-93, 2017. Singapore: Springer.

[9] J. S. C. Yim and P. Moses, "Work factors and teacher satisfaction: The mediating effect of cynicism toward educational change," Issues in Educational Reearch., vol. 26, no. 4, pp. 694-709, 2016.

[10] MetLife Survey of the American Teacher, "Challenges for school leadership: A survey of teachers and principals," MetLife: New York, 2013.

[11] P. E. Spector, "Job satisfaction: Application, assessment, 
causes and consequences," Thousand Oaks, 1997.

[12] S. I. Dugguh and A. Dennis, "Job satisfaction theories: Traceability to employee performance in organizations," IOSR Journal of Business Management, vol. 16, no. 5, pp. 2319-7668, 2014.

[13] Smith, P. C., Balzer, W., Brannick, M., Chia, W., Eggleston, S., Gibson, W., Johnson, B., Josephson, H., Paul, K., Reilly, C., \& Whalen, M. (1987). The revised JDI: A facelift for an old friend. The Industrial - Organisational Psychologist, 24, $31-33$

[14] P. E. Lester, "Development and factor analysis of the Teacher Job Satisfaction Questionnaire (TJSQ)," Educational and Psychological Measurement, vol. 4, no. 1, pp. 223-233, 1987.

[15] V. B. Arias, F. P. Ponce, and D. E. Núñez, "Bifactor Models of Attention-Deficit/Hyperactivity Disorder (ADHD)," Assessment, no. October 2017.

[16] D. M. Dueber, "Bifactor indices calculator: A Microsoft excel-based tool to calculate indices relevant to bifactor CFA model," [Available at http://sites.education.uky.edu/a pslab/resources/], 2017.

[17] A. Rodriguez, S. P. Reise, and M. G. Haviland, "Evaluating bifactor models: Calculating and interpreting statistical indices," Psychological Methods, vol. 21, no. 2, pp. 137150,2016

[18] E. Solis, N. Antypa, J. M. Conijn, H. Kelderman, and W. Van Der Does, "Psychometric properties of the Leiden Index of Depression Sensitivity ( LEIDS )," vol. 29, no. 2, pp. 158-171, 2017. 